\title{
Thermodynamics and Oxidation Behaviour of Crystalline Silicon Carbide (3C) with Atomic Oxygen and Ozone
}

\author{
Chandrika Varadachari, Ritabrata Bhowmick, and Kunal Ghosh \\ Raman Centre for Applied and Interdisciplinary Sciences, 16 A Jheel Road, Calcutta 700 075, India \\ Correspondence should be addressed to Chandrika Varadachari, cv@rcais.res.in \\ Received 23 September 2012; Accepted 16 October 2012 \\ Academic Editors: Y. Fang, T. M. Inerbaev, and G. Polidori
}

Copyright ( $\odot 2012$ Chandrika Varadachari et al. This is an open access article distributed under the Creative Commons Attribution License, which permits unrestricted use, distribution, and reproduction in any medium, provided the original work is properly cited.

Thermodynamics of oxidation of crystalline silicon carbide (cubic form) by atomic oxygen $(\mathrm{O})$ and ozone $\left(\mathrm{O}_{3}\right)$ was derived to understand the thermodynamic stability of $\mathrm{SiC}$ in the upper atmosphere. Equilibrium constants and equilibrium partial pressures were computed for each of eight possible reactions of $\mathrm{SiC}$ with $\mathrm{O}$ and $\mathrm{O}_{3}$. Equilibrium activity diagrams were derived, showing the most stable oxidation products of $\mathrm{SiC}$, represented in temperature-oxygen pressure $\left(T-P_{\mathrm{O}_{\mathrm{O}}}\right) 2 \mathrm{D}$ diagrams. Programs were developed in Mathematica. The diagrams provide an understanding of the oxidation routes of SiC under changing levels of $\mathrm{O} / \mathrm{O}_{3}$ and temperature, as encountered during reentry of space vehicles. At high levels of the volatiles, $\mathrm{CO}_{2}, \mathrm{CO}$, and $\mathrm{SiO}$ and temperatures between 1000 and $1500 \mathrm{~K}$, oxidation by atomic oxygen or ozone first produced $\mathrm{SiO}_{2}+\mathrm{C}$ followed by $\mathrm{SiO}_{2}+\mathrm{CO}$ and finally $\mathrm{SiO}_{2}+\mathrm{CO}_{2}$. When volatiles were at very low pressures, the sequence of oxidation was $\mathrm{SiO}+\mathrm{CO}$ followed by either $\mathrm{SiO}{ }_{2}+\mathrm{CO}$ or $\mathrm{SiO}+\mathrm{CO}_{2}$ and finally $\mathrm{SiO}_{2}+\mathrm{CO}_{2}$. Stability of $\mathrm{SiC}$ in ozone was much lower than in atomic oxygen. With both oxidants, the oxidation of the $\mathrm{Si}$ in $\mathrm{SiC}$ occurred prior to the oxidation of $\mathrm{C}$. Implications for mechanisms of thermal protection are discussed.

\section{Introduction}

Silicon carbide is an important material for space applications. It is a particularly useful thermal protection system for very high temperature zones like nose-cones in reentry vehicles. Since temperatures may reach $1700^{\circ} \mathrm{C}$ or higher, oxidation is a major problem and limits the temperatures to which $\mathrm{SiC}$ can be used. Several experimental studies on the oxidation of $\mathrm{SiC}$ with $\mathrm{O}_{2}$ have been reported. It was observed [1] that oxidation of $\mathrm{SiC}$ between $900-1600^{\circ} \mathrm{C}$ resulted in a surface layer of $\mathrm{SiO}_{2}$ that formed a protective film. The oxidation of $\mathrm{C}-\mathrm{SiC}$ heat shield materials under reentry conditions $\left(50-3500 \mathrm{~Pa}\right.$ and $1300-1700^{\circ} \mathrm{C}$ ) showed that a protective $\mathrm{SiO}_{2}$ layer was formed [2], and oxidation was insignificant as long as this silica layer was present. Others [3] observed etching of the surface and surface segregation of carbon. From photoemission studies on the $\mathrm{SiC}$ surface [4], it was concluded that oxygen is incorporated into the $\mathrm{Si}$ surface even at the smallest exposures to $\mathrm{O}_{2}$, but there was no discernible change on the C-terminated surface. Studies have confirmed that the rate controlling process is the diffusion of $\mathrm{O}_{2}$ through the solid $\mathrm{SiO}_{2}$ on the surface [5]. Mogilevsky and Zangvil [6] modelled the oxidation of SiC-reinforced mullite-zirconia matrix composites and evaluated oxygen permeabilities of the matrix as well as the silica layer. Oxidation kinetics in the temperature range of $1200-1350^{\circ} \mathrm{C}$ showed [7] a parabolic behaviour, which indicated a diffusion-controlled mechanism. In high vacuum, the surface composition of $\alpha$-SiC $(000 \overline{1})$ changed as a function of temperature due to oxide formation, yielding graphitic surface carbon [8]. Thermodynamic modelling of the reactions of oxygen with $\mathrm{SiC}$ has also been reported $[3,9]$. Phase diagrams of Si-C-O (oxygen) system are available in the literature $[10,11]$ as either triangular diagrams (Si-C-O) or biaxial diagrams $\left(\mathrm{T}-\mathrm{SiC} / \mathrm{SiO}_{2}\right)$.

Three layers of the atmosphere are involved in the oxidation reactions that occur during re-entry, namely, the 
TABLE 1: Reactions of $\mathrm{SiC}$ with $\mathrm{O}$ and $\mathrm{O}_{3}$.

\begin{tabular}{ccc}
\hline & Reactions with atomic oxygen & Reactions with ozone \\
\hline 1 & $\mathrm{SiC}+4 \mathrm{O} \rightarrow \mathrm{SiO}_{2}+\mathrm{CO}_{2}$ & $\mathrm{SiC}+4 / 3 \mathrm{O}_{3} \rightarrow \mathrm{SiO}_{2}+\mathrm{CO}_{2}$ \\
2 & $\mathrm{SiC}+2 \mathrm{O} \rightarrow \mathrm{SiO}+\mathrm{CO}$ & $\mathrm{SiC}+2 / 3 \mathrm{O}_{3} \rightarrow \mathrm{SiO}+\mathrm{CO}$ \\
3 & $\mathrm{SiC}+3 \mathrm{O} \rightarrow \mathrm{SiO}_{2}+\mathrm{CO}$ & $\mathrm{SiC}+\mathrm{O}_{3} \rightarrow \mathrm{SiO}_{2}+\mathrm{CO}$ \\
4 & $\mathrm{SiC}+2 \mathrm{O} \rightarrow \mathrm{SiO}_{2}+\mathrm{C}$ & $\mathrm{SiC}+2 / 3 \mathrm{O}_{3} \rightarrow \mathrm{SiO}_{2}+\mathrm{C}$ \\
5 & $\mathrm{SiC}+3 \mathrm{O} \rightarrow \mathrm{SiO}+\mathrm{CO}_{2}$ & $\mathrm{SiC}+\mathrm{O}_{3} \rightarrow \mathrm{SiO}+\mathrm{CO}_{2}$ \\
6 & $\mathrm{SiC}+\mathrm{O} \rightarrow \mathrm{SiO}+\mathrm{C}$ & $\mathrm{SiC}+1 / 3 \mathrm{O}_{3} \rightarrow \mathrm{SiO}+\mathrm{C}$ \\
7 & $\mathrm{SiC}+2 \mathrm{O} \rightarrow \mathrm{Si}+\mathrm{CO}_{2}$ & $\mathrm{SiC}+2 / 3 \mathrm{O}_{3} \rightarrow \mathrm{Si}+\mathrm{CO}_{2}$ \\
8 & $\mathrm{SiC}+\mathrm{O} \rightarrow \mathrm{Si}+\mathrm{CO}$ & $\mathrm{SiC}+1 / 3 \mathrm{O}_{3} \rightarrow \mathrm{Si}+\mathrm{CO}$ \\
\hline
\end{tabular}

troposphere, stratosphere, and mesosphere-lower thermosphere. The troposphere extends to about $18 \mathrm{~km}$ at the equator and $8 \mathrm{~km}$ at the poles. Tropospheric chemistry would be dominated by oxidation with molecular oxygen whose partial pressures vary from about 0.2 bar to $10^{-3}$ bar at the tropopause $[12,13]$. The stratosphere extends from $15-50 \mathrm{~km}$ above the Earth. Atmospheric chemistry of the stratosphere is dominated by ozone, with highest concentrations at 15-30 kilometres above the Earth's surface. Partial pressures of ozone here vary from about $5-30 \times 10^{-9}$ bar [13]. The mesosphere is located about $50-85 \mathrm{~km}$ above Earth's surface, and the lower thermosphere is located between 80 and $180 \mathrm{~km}$. Within this layer, temperature decreases with increasing altitude. Two strong photodissociation continua, the Schumann-Runge continuum, and the weaker Herzberg continuum produce atomic oxygen $(\mathrm{O})$ by breakdown of $\mathrm{O}_{2}$ [12].

To obtain an understanding of the chemical behaviour of $\mathrm{SiC}$ in the upper atmosphere, knowledge of the nature of reactions with atomic oxygen and ozone is important. The objective here was a theoretical investigation of the thermodynamics of oxidation of $\mathrm{SiC}$ by $\mathrm{O}$ and $\mathrm{O}_{3}$. Equilibrium constants were computed for all possible reaction pathways. Equilibrium activity diagrams were derived to show the effects of temperature and pressures of $\mathrm{O}$ and $\mathrm{O}_{3}$ on the oxidation of $\mathrm{SiC}$. The resulting diagrams showed the thermodynamically stable oxidation products under variable temperatures and partial pressures of oxidants. Possible pathways of oxidation were proposed. The studies would be useful for modelling chemical transformations of $\mathrm{SiC}$ in the stratosphere and mesosphere-lower thermosphere.

\section{Theory and Methods}

Oxidation of $\mathrm{SiC}$ with $\mathrm{O} / \mathrm{O}_{3}$ can occur in eight different ways. These reactions are stoichiometrically represented in Table 1.

Standard free energy change of these reactions at temperature $T,\left(\Delta \mathrm{G}_{r, T}^{0}\right)$ was obtained from the standard free energy of formation $\left(\Delta \mathrm{G}_{f, T}^{0}\right)$ as:

$$
\Delta \mathrm{G}_{r, T}^{0}=\sum \Delta \mathrm{G}_{f, T}^{0} \text { (products) }-\sum \Delta \mathrm{G}_{f, T}^{0} \text { (reactants), }
$$

which is related to equilibrium constant $K$ as

$$
\Delta \mathrm{G}_{r, T}^{0}=-R T \ln k=-R T \ln \left(\frac{\Pi a_{p}^{\nu}}{\Pi a_{r}^{\kappa}}\right),
$$

where $a_{p}$ and $a_{r}$ are activities of products and reactants, respectively, and the power terms refer to the stoichiometric amounts of the compounds participating in the reaction. Total free energy change under nonstandard conditions was obtained from the relation:

$$
\Delta \mathrm{G}_{r, T}=\Delta \mathrm{G}_{r, T}^{0}+R T \ln \left(\frac{\Pi a_{p}^{\nu}}{\prod a_{r}^{\kappa}}\right) .
$$

Equilibrium activity diagrams were derived from net Gibbs free energy changes $\left(\Delta \mathrm{G}_{r, T}\right)$. This allows us to include the effect of variables (such as partial pressures of $\mathrm{CO}, \mathrm{CO}_{2}$, and $\mathrm{SiO})$ that have important contributions to oxidation. The dominant reaction will be the one with the most negative total free energy change $\left(\Delta \mathrm{G}_{r, T}\right)$.

The process involved (i) computation of free energy changes for all possible reactions in a system, (ii) comparison to obtain the reaction showing greatest reduction in free energy, and (iii) derivation of the limiting conditions for the reaction to have largest free energy reduction compared to all other reactions. Thus, the values of $\Delta G_{r, T}$ for all equations in Table 1 were derived at small intervals of the variables $\left(T-\log P_{\mathrm{O} / \mathrm{O}_{3}}\right)$. These values were compared at each value of the variables, and subsequently boundary conditions were obtained.

Thermodynamic data for the computations were obtained from the literature [14]. Equilibrium activity diagrams showing partial pressure-temperature relations were then computed. For derivation of equilibrium activity diagrams, a program OXID2D was developed in Mathematica (see Supplementary Materials available online at doi:10.542/2012/108781). The main program has 2 subroutines (SubOXID_1 and SubOXID_2), which derive the standard free energy change of the oxidation reaction $\left(\Delta \mathrm{G}_{r, T}^{0}\right)$ and equilibrium ozone $\left(\mathrm{O}_{3}\right)$ pressures at lower and higher temperatures $T$ (flow chart in Figure 1). The first sub-routine (SubOXID_1) is for reactions in the lower temperature range $(298.15-1900 \mathrm{~K})$, where $\mathrm{SiO}_{2}$ is in the solid phase; the other sub-routine (SubOXID_2) is for reactions at temperatures above the melting point of $\mathrm{SiO}_{2}(2000-3200 \mathrm{~K})$. Inputs required are the gas constant $R$ (in $\mathrm{kJ} / \mathrm{mole}$ ) and values of $\log P_{\mathrm{CO}_{2}}, \log P_{\mathrm{CO}}$, and $\log P_{\mathrm{SiO}}$ (Figure 1). Other input data are temperatures and the corresponding standard free energy of formation $\left(\Delta \mathrm{G}_{f, T}^{0}\right)$ of all compounds in the reactants and products. Then, for each temperature $T, \Delta \mathrm{G}_{r, T}^{0}$ is derived by (1). The list of temperature- $\Delta \mathrm{G}_{r, T}^{0}$ is exported for the main program. Additionally, equilibrium ozone $\left(\mathrm{O}_{3}\right)$ pressures are computed for constant values of $\log P_{\mathrm{CO}_{2}}, \log P_{\mathrm{CO}}$, and $\log P_{\mathrm{SiO}}$ and plotted as $T$ versus $\log P_{\mathrm{O}_{3}}$. The subroutines are available as supplementary information.

The main program OXID2D (supplemental file) then derives the equilibrium boundaries from total free energy change of reaction $\left(\Delta \mathrm{G}_{r, T}\right)$ using (3). To compute the values of $\Delta \mathrm{G}_{r, T}$, activities of $\mathrm{CO}_{2}, \mathrm{CO}$, and $\mathrm{SiO}$ have to be defined. 


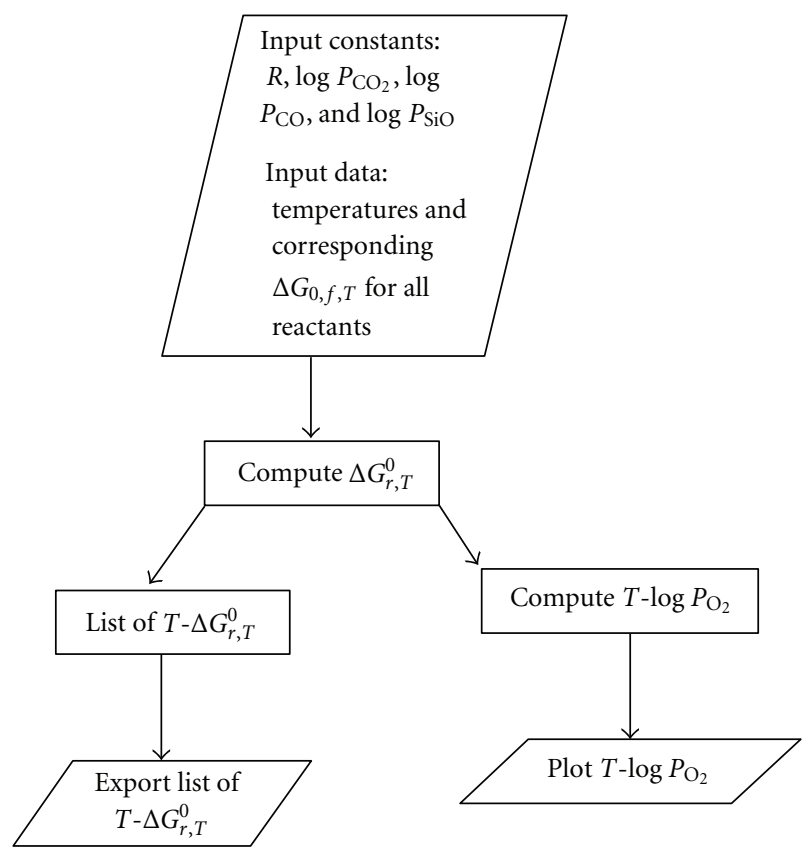

FIGURE 1: Flowchart for subroutine program SubOXID to compute equilibrium ozone/atomic oxygen activity and standard free energy change of reaction with temperature.

Here, these were assigned constant values representing four different conditions, namely, $P_{\mathrm{CO}_{2} / \mathrm{CO} / \mathrm{SiO}}=10^{0}, 10^{-3}, 10^{-7}$, and $10^{-10}$. The next step of the program (flow diagram in Figure 2) defines minimum and maximum temperatures and ozone $\left(\mathrm{O}_{3}\right)$ partial pressures $\left(\log P_{\mathrm{O}_{3}}\right)$ and the respective increment intervals. A list of the variables, $T-P_{\mathrm{O}_{3}}$, is then generated. The data from SubOXID_1 \& 2 are imported, and the relation between $T-\Delta \mathrm{G}_{r, \mathrm{~T}}^{0}$ is fitted into a linear regression equation. From this equation, $\Delta \mathrm{G}_{r, T}^{0}$ values are derived for every value of temperature increment. Subsequently, using (3), $\Delta \mathrm{G}_{r, T}$ values are computed from the values of $\Delta \mathrm{G}_{r, T}^{0}$ using $P_{\mathrm{CO}_{2}}, P_{\mathrm{CO}}$, and $P_{\mathrm{SiO}}$ as constants, $T$ and $P_{\mathrm{O}_{3}}$ as variables, temperature range $T=500$ to $3200 \mathrm{~K}$, ozone levels $\log P_{\mathrm{O}_{3}}=1$ to -50 , and increment intervals of $T=5 \mathrm{~K}$ and $\log P_{\mathrm{O}_{3}}=1$. Only negative values of $\Delta \mathrm{G}_{r, T}$ are retained. Derived $\Delta \mathrm{G}_{r, T}$ values for all the reactions are combined into separate lists for each $T-\log P_{\mathrm{O}_{3}}$. In each list, the $\Delta \mathrm{G}_{r, T}$ values are compared, and the reaction showing the most negative value is assigned to that $T-\log P_{\mathrm{O} 3}$ as the most favourable (stable) reaction. The reaction is identified and represented by a coloured box at that particular value of $T-\log P_{\mathrm{O}_{3}}$. The process is repeated over all values of $T-\log P_{\mathrm{O}_{3}}$, and all points are combined in a single plot. A similar method was earlier used to derive equilibrium diagrams for nonstoichiometric clay minerals in aqueous environments [15] and also to derive fuzzy phase diagrams representing 464 metastable minerals [16].

Equilibrium diagrams in the atomic oxygen system were derived with the same program after substituting the $\Delta \mathrm{G}_{f, T}^{0}$ values for $\mathrm{O}$ and changing the reaction stoichiometries according to those shown in Table 1.
TABLE 2: Equilibrium $\mathrm{O}, \mathrm{O}_{3}$ pressures for oxidation of $\mathrm{SiC}, \mathrm{Si}$, and C.

\begin{tabular}{lcccccc}
\hline \multirow{2}{*}{ Reaction } & \multicolumn{2}{c}{$1000 \mathrm{~K}$} & \multicolumn{2}{c}{$2000 \mathrm{~K}$} & \multicolumn{2}{c}{$3000 \mathrm{~K}$} \\
& $\log P_{\mathrm{O}}$ & $\log P_{\mathrm{O}_{3}}$ & $\log P_{\mathrm{O}}$ & $\log P_{\mathrm{O}_{3}}$ & $\log P_{\mathrm{O}}$ & $\log P_{\mathrm{O}_{3}}$ \\
\hline 1 & -23.66 & -52.61 & -9.05 & -24.89 & -4.20 & -15.77 \\
2 & -18.22 & -36.30 & -9.63 & -26.64 & -6.67 & -23.17 \\
3 & -24.87 & -56.24 & -10.04 & -27.88 & -5.13 & -18.54 \\
4 & -27.17 & -63.15 & -9.74 & -26.97 & -4.01 & -15.20 \\
5 & -18.82 & -38.11 & -8.44 & -23.07 & -4.92 & -17.94 \\
6 & -16.18 & -30.17 & -8.61 & -23.60 & -5.98 & -21.11 \\
7 & -18.44 & -36.95 & -7.72 & -20.92 & -4.29 & -16.05 \\
8 & -16.85 & -32.19 & -9.38 & -25.89 & -7.15 & -24.62 \\
9 & -19.59 & -40.41 & -9.88 & -27.39 & -6.18 & -21.72 \\
10 & -28.88 & -68.27 & -10.37 & -28.87 & -4.11 & -15.50 \\
11 & -20.26 & -42.43 & -10.65 & -29.69 & -7.36 & -25.23 \\
12 & -20.14 & -42.07 & -8.35 & -22.81 & -4.40 & -16.35 \\
\hline
\end{tabular}

\section{Results and Discussion}

3.1. Equilibrium Constants and Equilibrium Gas Pressure. Equilibrium constant $(\log k)$-temperature relationships for 8 types of oxidations of cubic (3C) $\mathrm{SiC}$ (Table 1) are presented in Figure 3. $\log k$ values were highly positive and suggested that all oxidations were thermodynamically favourable. The oxidation reaction producing $\mathrm{SiO}_{2}+\mathrm{CO}_{2}$ had highest values of $\log k$ for both the oxidants $\mathrm{O}_{2}$ and $\mathrm{O}_{3}$. This was followed by $\mathrm{SiO}_{2}+\mathrm{CO}$ and then $\mathrm{SiO}_{2}+\mathrm{C}$. At higher temperatures, there was a crossover, with $\mathrm{SiO}+\mathrm{CO}_{2}$ having higher $\log k$ than $\mathrm{SiO}_{2}+$ C. In general, reactions producing $\mathrm{SiO}_{2}$ or $\mathrm{CO}_{2}$ were energetically more favourable than reactions producing $\mathrm{SiO}$ or $\mathrm{CO}$. The value of $k$ reduced sharply with temperature for all reactions except (6) and (8).

Equilibrium constants for reactions with $\mathrm{O}_{3}$ were generally smaller than with $\mathrm{O}$. Thus, at $1000 \mathrm{~K}, \log k$ values for the formation of $\mathrm{SiO}_{2}+\mathrm{CO}_{2}$ from $\mathrm{O}$ and $\mathrm{O}_{3}$ were 94.6 and 70.2 , respectively; at $2000 \mathrm{~K}$, these values were 36.2 and 33.2 . Oxidation to $\mathrm{SiO}+\mathrm{CO}_{2}$ at $1000 \mathrm{~K}$ showed a similar trend with equilibrium constants of 56.3 and 38.0 for reactions with $\mathrm{O}$ and $\mathrm{O}_{3}$, respectively.

Equilibrium partial pressures of $\mathrm{O}$ and $\mathrm{O}_{3}$ for oxidation of $\mathrm{SiC}$ (under standard pressures of $\mathrm{CO}_{2}, \mathrm{CO}$ and $\mathrm{SiO}$ ) are presented in Table 2. Oxidation was thermodynamically favourable at $1000 \mathrm{~K}$ with $\log P_{\mathrm{O}}$ levels as low as -29 ; reactions forming $\mathrm{SiO}_{2}$ occurred at lower $\mathrm{O}$ pressures than those forming $\mathrm{SiO}$. At $3000 \mathrm{~K}$, equilibrium $\log P_{\mathrm{O}}$ levels were about -6 for $\mathrm{SiO}$ formation, and unlike trends at $1000 \mathrm{~K}, \mathrm{SiO}_{2}$ was formed at higher O levels compared to SiO. Oxidations with $\mathrm{O}_{3}$ (Table 2) followed a similar trend. However, equilibrium activities for oxidation with ozone were substantially lower than for atomic oxygen.

Partial pressures of the volatiles, $\mathrm{CO}_{2}, \mathrm{CO}$, and $\mathrm{SiO}$ had a significant impact in lowering the pressures of $\mathrm{O} / \mathrm{O}_{3}$ at which oxidation began. Reactions forming $\mathrm{SiO}$ (Figure 4) were particularly affected by increasing levels of the volatiles, as observed by the steep slopes. Oxidation to $\mathrm{SiO}_{2}$ was 


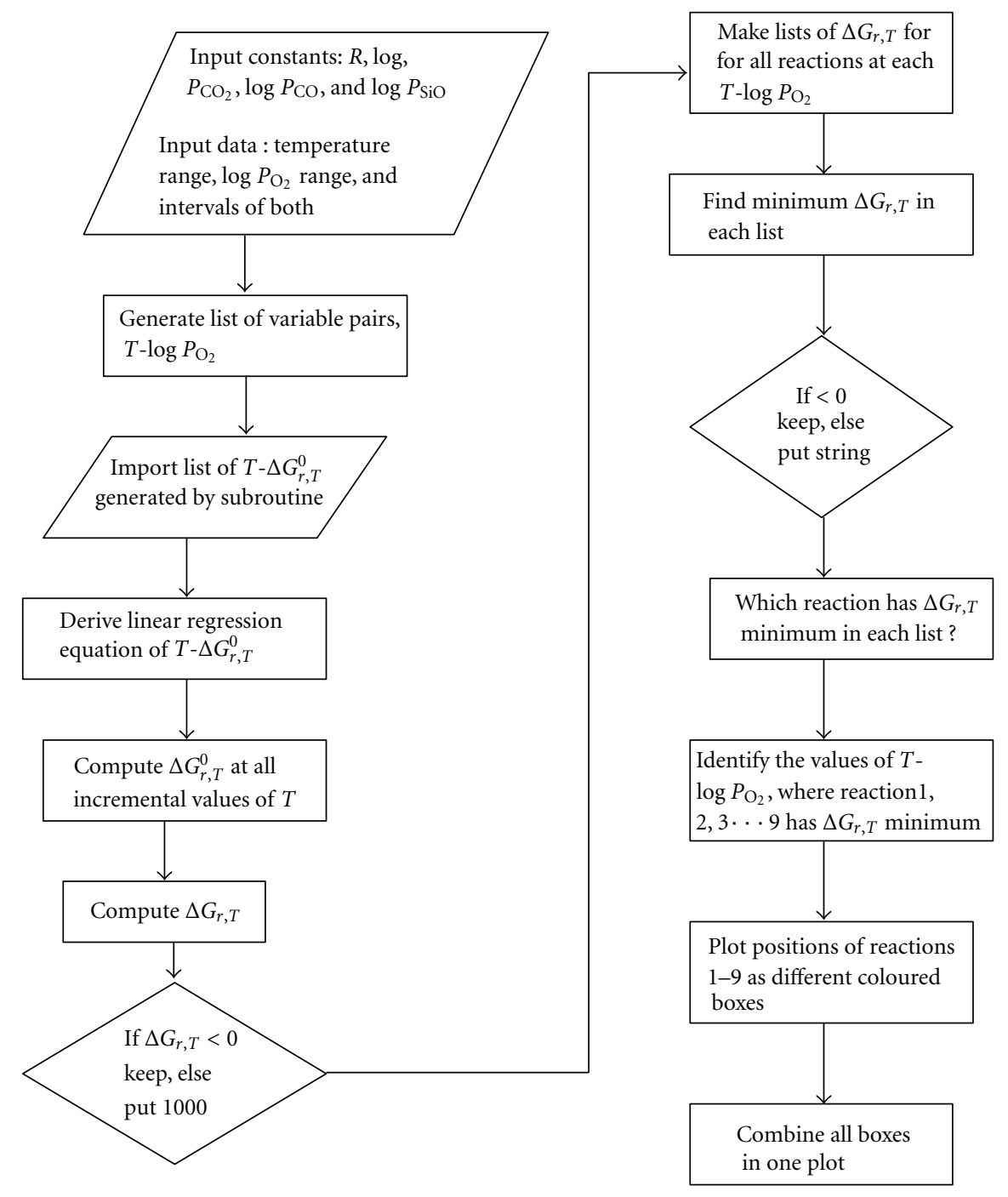

FIgURE 2: Flowchart for the program OXID2D to derive oxidation phase diagram.

comparatively less affected by the levels of volatile products. This was true for both oxidants, $\mathrm{O}$ and $\mathrm{O}_{3}$. Reactivity of $\mathrm{SiC}$ towards ozone was particularly remarkable. Even in the presence of substantial levels of the oxidation inhibitors, oxidation to $\mathrm{SiO}$ could occur at $\mathrm{O}_{3}$ pressures as low as $10^{-30}$ atm, which is about $10^{17}$ times lower than the level of atomic oxygen required for the same oxidation.

3.2. Oxidation Equilibrium Diagrams. Reaction equilibrium diagrams of thermodynamically stable products formed, when $\mathrm{SiC}$ (cubic) was exposed to various $\mathrm{O}$ pressures at different temperatures and different levels of $\mathrm{CO}_{2}, \mathrm{CO}$, and $\mathrm{SiO}$, are presented in Figures $5(\mathrm{a})-5(\mathrm{~d})$. Figure 5(a) shows the nature of products under standard (unit) pressures of gaseous products $\mathrm{CO}_{2}, \mathrm{CO}$, and $\mathrm{SiO}$. At temperatures below $1500 \mathrm{~K}$, as $\mathrm{O}$ pressure increased, $\mathrm{SiO}_{2}$ and $\mathrm{C}$ were the first reaction products. On further increase in $\mathrm{O}$ pressure, $\mathrm{SiO}_{2}$ and $\mathrm{CO}_{2}$ were formed (at $\log P_{\mathrm{O}} \gtrsim-18$ ). At temperatures above $1500 \mathrm{~K}$, the initial products were $\mathrm{SiO}_{2}+\mathrm{CO}$ followed by $\mathrm{SiO}_{2}+\mathrm{CO}_{2}$ at higher $\mathrm{O}$ pressures. In the region beyond $\sim 2300 \mathrm{~K}$, oxidation proceeded from $\mathrm{SiO}+\mathrm{CO}$ to $\mathrm{SiO}_{2}+$ $\mathrm{CO}$ and then to $\mathrm{SiO}_{2}+\mathrm{CO}_{2}$. Significantly, the sequence of oxidation also suggested that oxidation of the $\mathrm{Si}$ in $\mathrm{SiC}$ occurred prior to the oxidation of $\mathrm{C}$.

As levels of $\mathrm{CO}, \mathrm{CO}_{2}$, and $\mathrm{SiO}$ were reduced to $10^{-3} \mathrm{~atm}$ (Figure 5(b)), the stability zone of $\mathrm{SiC}$ was reduced from an upper $P_{\mathrm{O}}$ limit of $10^{-12}$ to $10^{-18}$. Above temperatures of $\sim 1800 \mathrm{~K}, \mathrm{SiO}$ was the first oxidation product. Further oxidation produced either $\mathrm{SiO}_{2}+\mathrm{CO}$ or $\mathrm{SiO}+\mathrm{CO}_{2}$ depending on whether temperature was above or below $2350 \mathrm{~K}$. Temperature for formation of $\mathrm{SiO}$ was greatly lowered as levels of $\mathrm{CO}, \mathrm{CO}_{2}$, and $\mathrm{SiO}$ were further reduced (Figures 5(c) and 5(d)). Thus, $\mathrm{SiO}$ was formed at $\sim 1100 \mathrm{~K}$ when pressures of $\mathrm{CO}, \mathrm{CO}_{2}$, and $\mathrm{SiO}$ were at $10^{-10} \mathrm{~atm}$ (Figure 5(d)); equilibrium pressure for stability of $\mathrm{SiC}$ also dropped sharply to about $10^{-20}$ atm.

Briefly, at lower temperatures and higher levels of volatiles (Figures 5(a) and 5(b)), oxidation with atomic oxygen first produced $\mathrm{SiO}_{2}+\mathrm{C}$ followed by $\mathrm{SiO}_{2}+\mathrm{CO}_{2}$. 

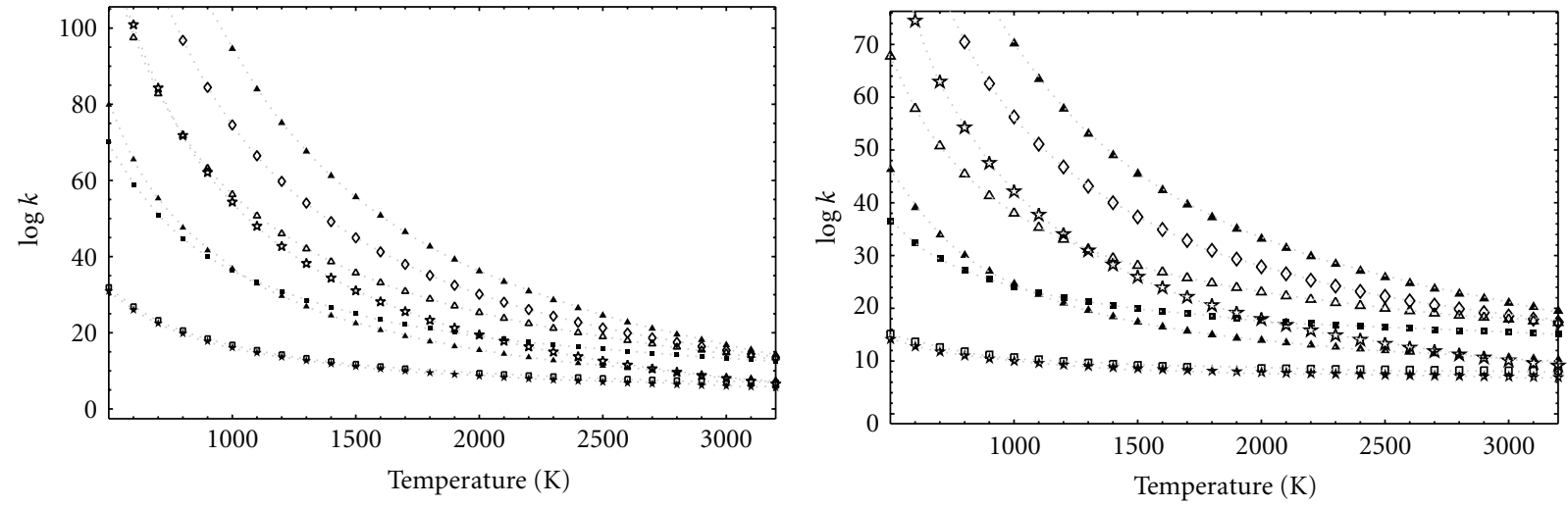

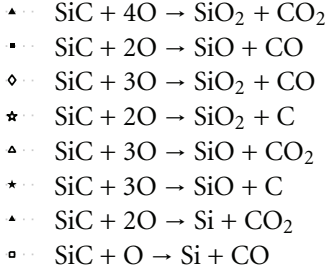

(a)

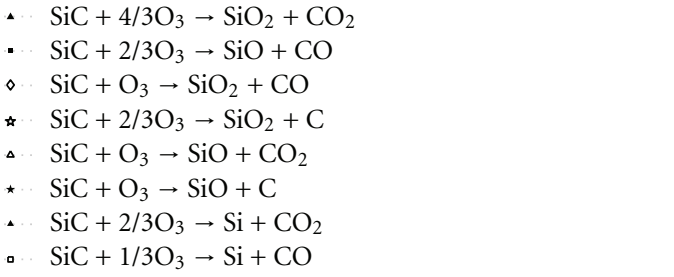

(b)

Figure 3: Equilibrium constant $(K)$-temperature $(T)$ relations for reactions of (a) $\mathrm{SiC}$ with $\mathrm{O}$ and (b) $\mathrm{SiC}$ with $\mathrm{O}_{3}$.

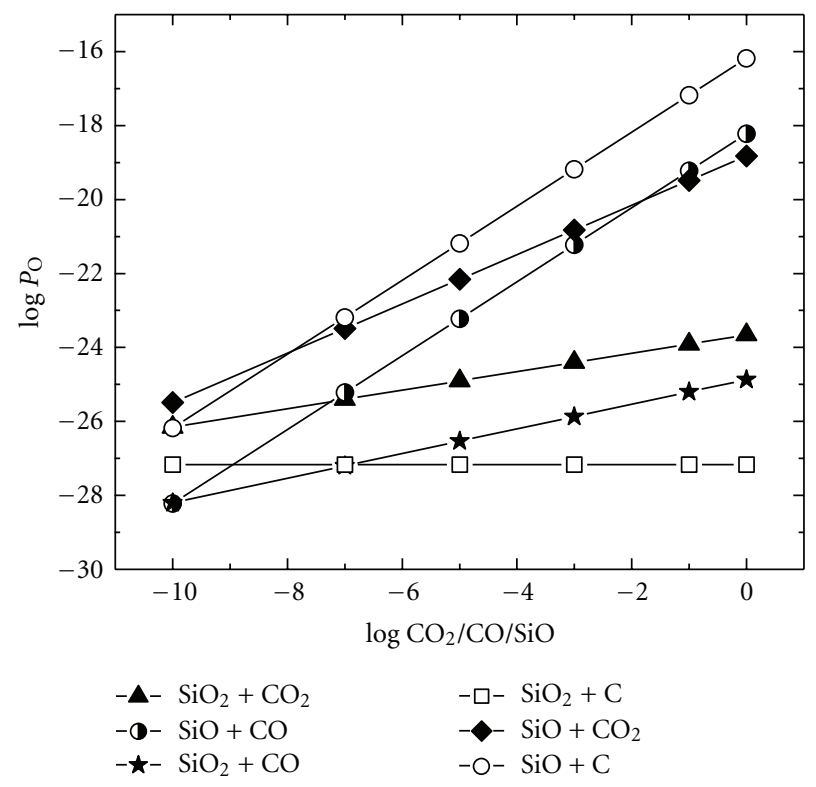

(a)

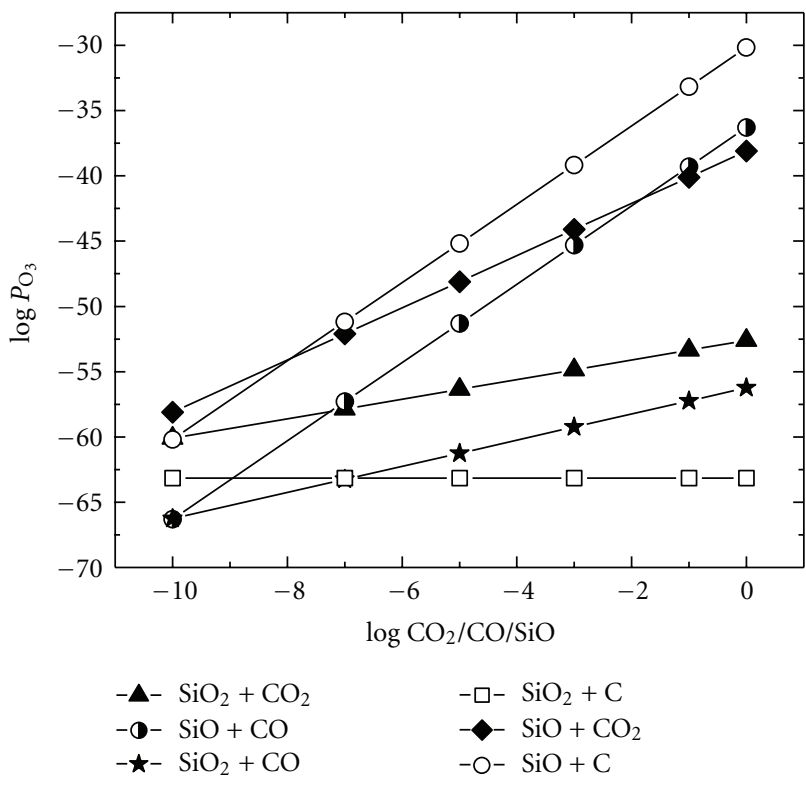

(b)

FIgURE 4: Relationship between equilibrium partial pressures of (a) $\mathrm{O}$ and (b) $\mathrm{O}_{3}$ and partial pressures of $\mathrm{CO}_{2} / \mathrm{CO} / \mathrm{SiO}$ in oxidation of $\mathrm{SiC}$.

Increasing temperature and reducing pressures of volatiles (Figures 5(c) and 5(d)) resulted in the oxidation sequence $\mathrm{SiO}+\mathrm{CO}$ then $\mathrm{SiO}+\mathrm{CO}_{2}$ and finally $\mathrm{SiO}_{2}+\mathrm{CO}_{2}$. Lower temperatures favoured the formation of $\mathrm{SiO}_{2}$ (passive oxidation), whereas $\mathrm{SiO}$ was formed at higher temperatures (active oxidation).

Stability of $\mathrm{SiC}$ in ozone was severely reduced compared

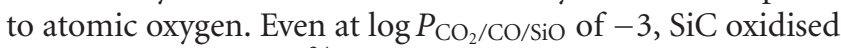
to $\mathrm{SiO}$ and $\mathrm{CO}$ at $10^{-34} \mathrm{~atm} \mathrm{O}_{3}$ and at $1600 \mathrm{~K}$ (Figure 6(b)).
There was no observable stability field of $\mathrm{SiC}$ (down to $\left.\log P_{\mathrm{O}_{3}}=-50\right)$ when pressures of volatiles were very low $\left(10^{-10} \mathrm{~atm}\right.$, Figure $\left.6(\mathrm{~d})\right)$. Oxidation products were similar to those observed with molecular and atomic oxygen. However, the stability field of $\mathrm{SiO}_{2}+\mathrm{CO}$ increased significantly. At lower temperatures, oxidation proceeded with the formation of $\mathrm{SiO}_{2}+\mathrm{CO}$ followed by $\mathrm{SiO}_{2}+\mathrm{CO}_{2}$. At higher temperatures, $\mathrm{SiO}+\mathrm{CO}$ formed first; this oxidised to $\mathrm{SiO}+\mathrm{CO}_{2}$ and finally to $\mathrm{SiO}_{2}+\mathrm{CO}_{2}$. 


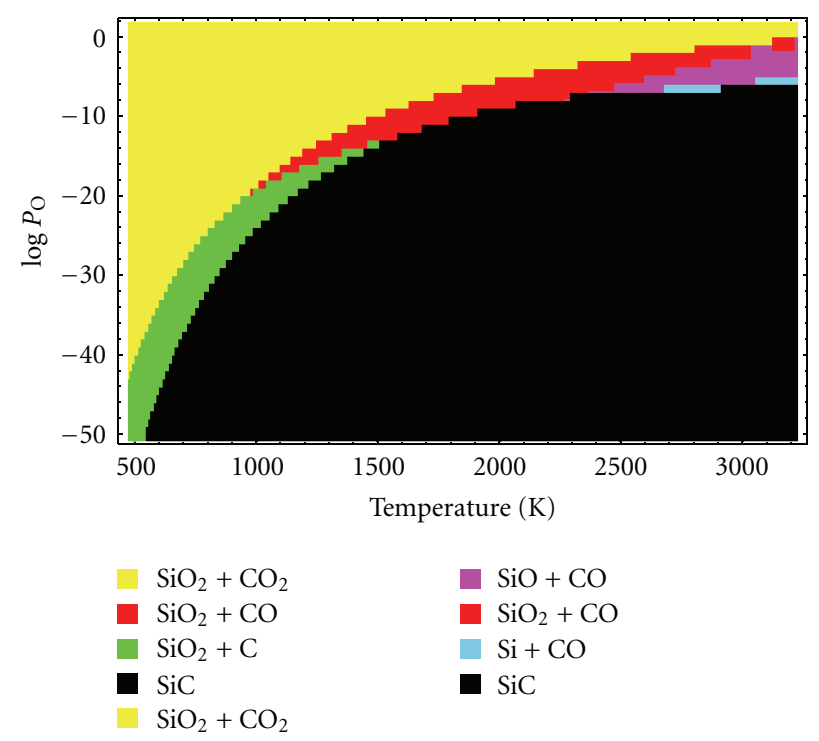

(a)

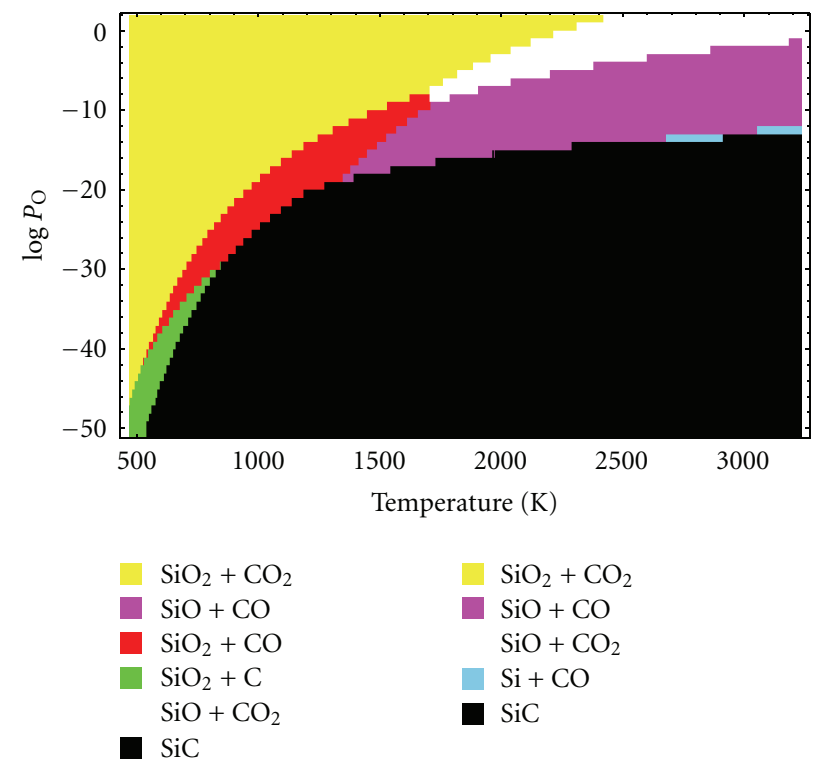

(c)
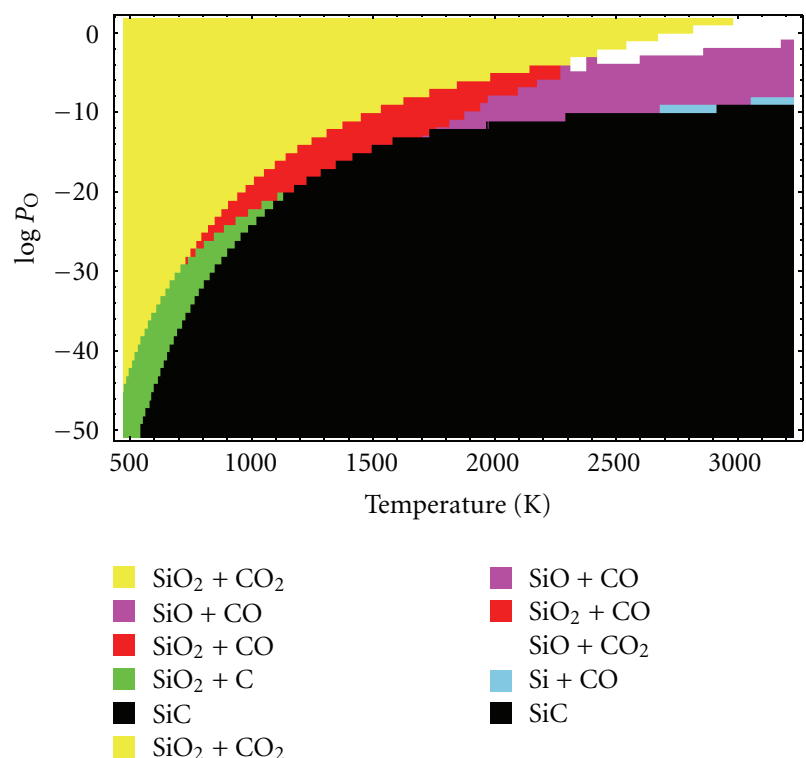

(b)
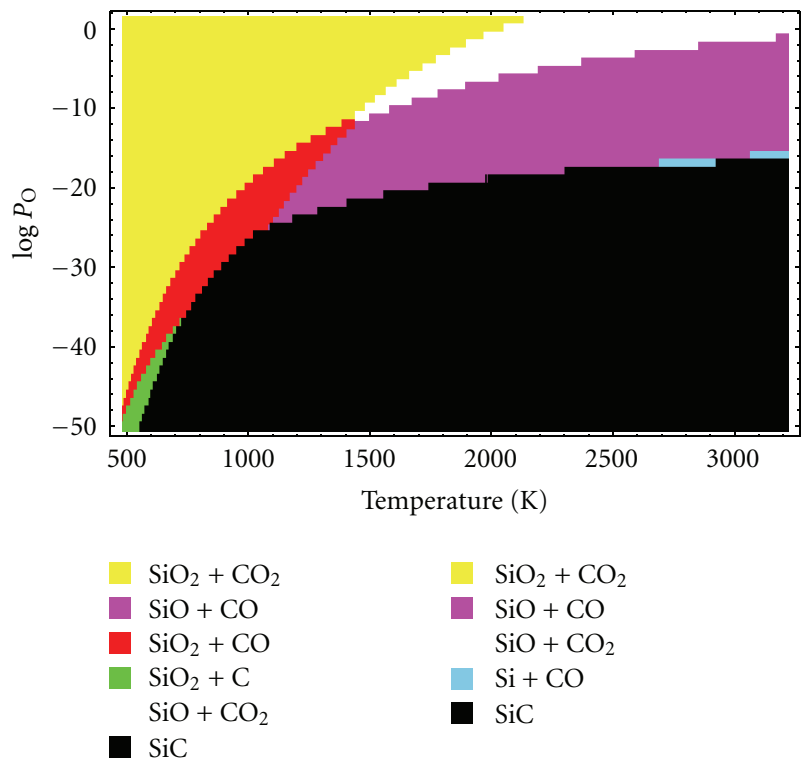

(d)

Figure 5: Equilibrium diagram of $\mathrm{SiC}$ oxidation with atomic oxygen $(\mathrm{O})$ at $(\mathrm{a}) \log P_{\mathrm{CO}_{2}}=0, \log P_{\mathrm{CO}}=0$, and $\log P_{\mathrm{SiO}}=0$, (b) $\log P_{\mathrm{CO}}=-3$, $\log P_{\mathrm{CO}}=-3$, and $\log P_{\mathrm{SiO}}=-3$, (c) $\log P_{\mathrm{CO}_{2}}=-7, \log P_{\mathrm{CO}}=-7$, and $\log P_{\mathrm{SiO}}=-7$, and (d) $\log P_{\mathrm{CO}_{2}}=-10, \log P_{\mathrm{CO}}=-10$, and $\log P_{\mathrm{SiO}}=-10$.

With regard to reactions at the surface of reentry vehicles, the diagrams suggest that at the initial phase (in the upper mesosphere, where temperatures fall as low as $200 \mathrm{~K}$, and the main oxidant is atomic oxygen) oxidation would mainly produce $\mathrm{SiO}_{2}$ and $\mathrm{CO}_{2}$. On entry into the stratosphere, under the conditions of temperature and ozone pressures encountered, $\mathrm{SiO}_{2}$ and $\mathrm{CO}_{2}$ would form. Since tropospheric oxygen levels are in the range of 0.2 bar to $10^{-3}$ bar at the tropopause [4], the implications are that $\mathrm{SiO}_{2}$ and $\mathrm{CO}_{2}$ would be the major oxidation products (provided $\mathrm{CO} / \mathrm{CO}_{2}$ levels are high, as in the presence of ablatives). The initial formation of $\mathrm{SiO}_{2}$ would result in a protective layer that would retard diffusion and further oxidation of $\mathrm{SiC}$. Although in the absence of $\mathrm{CO} / \mathrm{CO}_{2}$ producing ablatives the oxidation product would be $\mathrm{SiO}$, the initial coating of $\mathrm{SiO}_{2}$ would protect the bulk $\mathrm{SiC}$ from complete oxidation. Such a protective mechanism would be effective only below the melting point of $\mathrm{SiO}_{2}$, that is, $1996 \mathrm{~K}$. Above this temperature, complete oxidation can occur (since wind speeds would be sufficient to blow away the liquid $\mathrm{SiO}_{2}$ coating).

Experimental data on the oxidation of silicon carbide with ozone showed that oxidation rates in ozone-containing atmosphere were much higher than those in a pure oxygen 


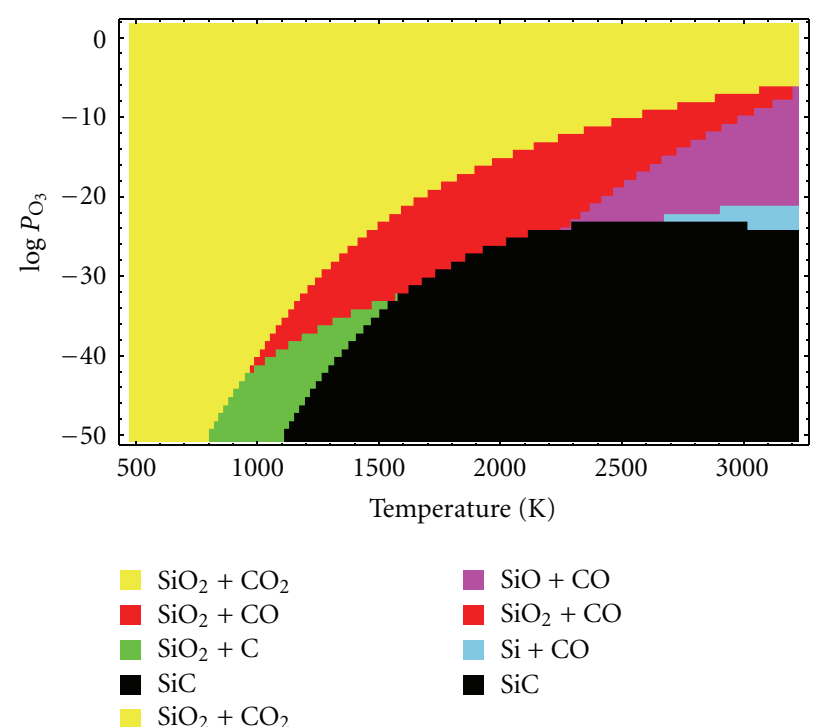

(a)

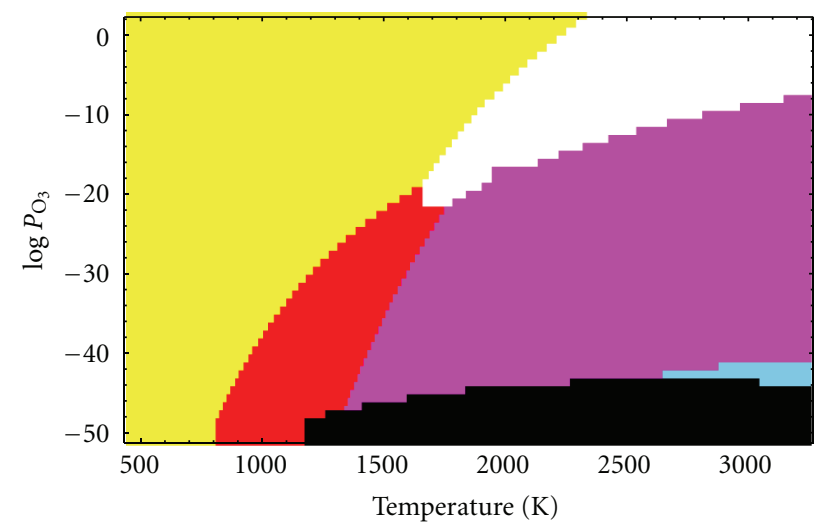
-1. $\mathrm{SiO}_{2}+\mathrm{CO}_{2}$
$\mathrm{SiO}+\mathrm{CO}$
$\mathrm{SiO}_{2}+\mathrm{CO}$
$\mathrm{SiO}+\mathrm{CO}_{2}$
- $\mathrm{SiC}$

$$
\begin{array}{ll} 
& \mathrm{SiO}_{2}+\mathrm{CO}_{2} \\
\mathrm{SiO}+\mathrm{CO} \\
\mathrm{SiO}+\mathrm{CO}_{2} \\
\mathrm{Si}+\mathrm{CO} \\
\mathrm{SiC}
\end{array}
$$

(c)

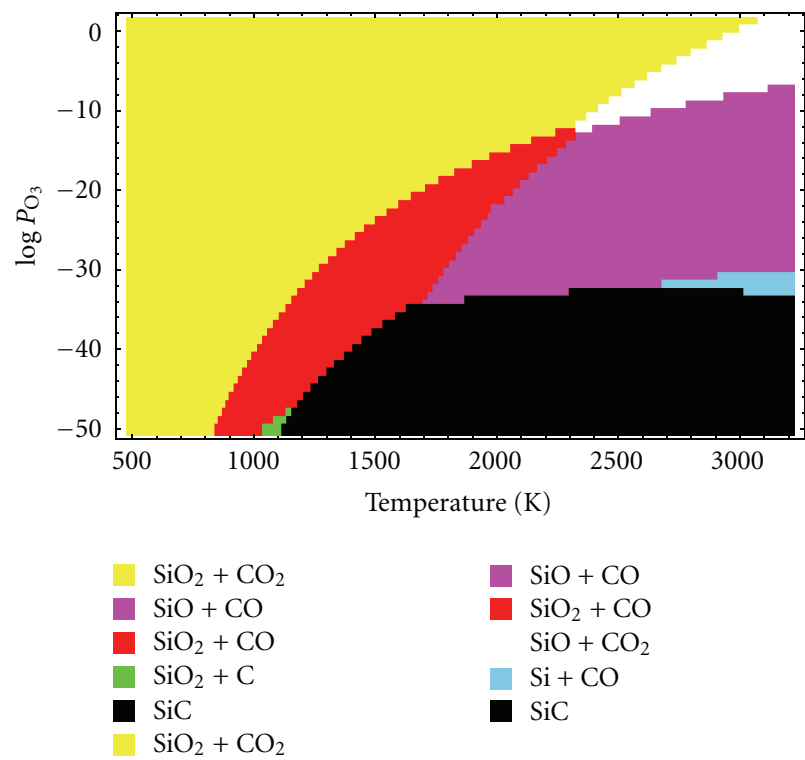

(b)

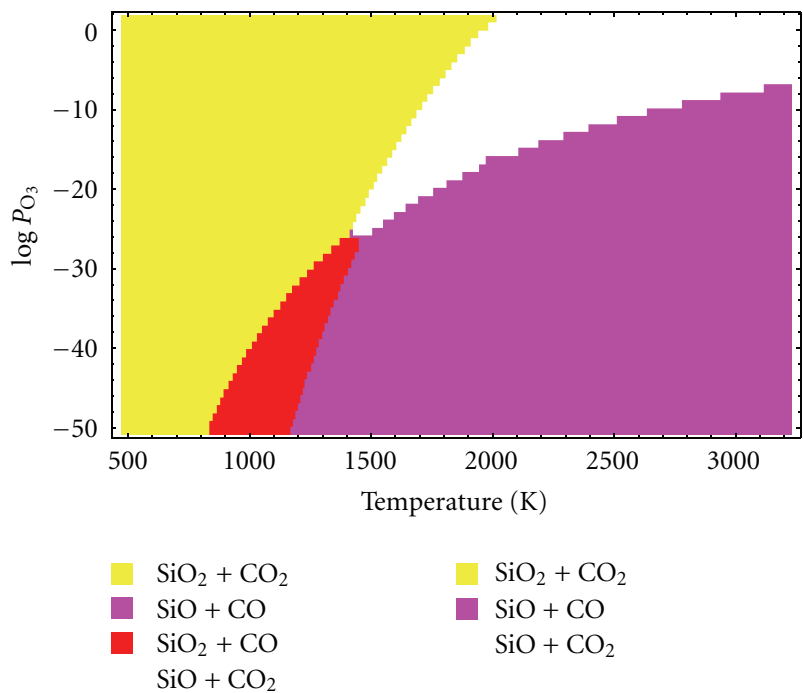

(d)

FIgure 6: Equilibrium diagram of $\mathrm{SiC}$ oxidation with ozone $\left(\mathrm{O}_{3}\right)$ at $(\mathrm{a}) \log P_{\mathrm{CO}_{2}}=0, \log P_{\mathrm{CO}}=0$, and $\log P_{\mathrm{SiO}}=0$, (b) $\log P_{\mathrm{CO}_{2}}=-3$, $\log P_{\mathrm{CO}}=-3$, and $\log P_{\mathrm{SiO}}=-3$, (c) $\log P_{\mathrm{CO}_{2}}=-7, \log P_{\mathrm{CO}}=-7$, and $\log P_{\mathrm{SiO}}=-7$, and (d) $\log P_{\mathrm{CO}_{2}}=-10, \log P_{\mathrm{CO}}=-10$, and $\log P_{\mathrm{SiO}}=-10$.

atmosphere [17]. In other experimental observations on oxidations with molecular oxygen, $\mathrm{SiO}_{2}$ has been observed to form a protective film on the surface of $\mathrm{SiC}$ between 900 and $1600^{\circ} \mathrm{C}[1]$; this has been verified under reentry conditions [5]. Protective action reduces when $\mathrm{SiO}_{2}$ begins to bubble at $3500 \mathrm{~Pa}$ and $1580^{\circ} \mathrm{C}$ [5]. Cracks form and become oxidation channels leading to rapid weight loss [13]. The oxidation behavior of the $\mathrm{SiC}$ indicated a two-step parabolic oxidation kinetics with formation of crystalline $\mathrm{SiO}_{2}$ film. Diffusion of oxygen through the $\mathrm{SiO}_{2}$ film becomes the rate-controlling step of reaction [18]. Charpentier et al. [19] observed with massive $\alpha$-SiC samples that the transition between passive and active oxidation occurred at $1300 \mathrm{~K}$ for an oxygen partial pressure of $0.2 \mathrm{~Pa}$ and at $1600 \mathrm{~K}$ for $100 \mathrm{~Pa}$. Our observation that the $\mathrm{Si}$ in $\mathrm{SiC}$ is more readily oxidized than the $\mathrm{C}$ is also corroborated by experimental studies [12] which show that even very small exposures to oxygen lead to an oxygenated $\mathrm{Si}$ terminated surface but without any change in the Cterminated surface.

\section{Conclusions}

Thermodynamics of oxidation reactions of $\mathrm{SiC}$ were studied by constructing a reaction equilibrium diagram of $\mathrm{SiC}$ 
with atomic oxygen and ozone. Equilibrium constant $(k)$ temperature relations were derived for all the eight possible ways in which oxidation could occur. In all reactions, $k$ values were observed to be highly positive and to decrease with temperature. The reaction forming $\mathrm{SiO}_{2}+\mathrm{CO}_{2}$ was thermodynamically the most favourable. Partial pressuretemperature relations suggest that equilibrium pressures are extremely low.

Derived oxidation equilibrium diagrams showed the thermodynamically most favoured oxidation products and the sequence of oxidation under various conditions. As SiC was exposed to increasing levels of $\mathrm{O}_{\text {or }} \mathrm{O}_{3}$, the first products were $\mathrm{SiO}_{2}+\mathrm{C}$, followed by $\mathrm{SiO}_{2}+\mathrm{CO} / \mathrm{SiO}+\mathrm{CO}_{2}$. High temperature and lower pressures of volatiles $\left(\mathrm{CO}, \mathrm{CO}_{2}\right.$, and $\mathrm{SiO}$ ) in the zone of oxidation favoured the formation of $\mathrm{SiO}$ over $\mathrm{SiO}_{2}$. Moreover, in the $\mathrm{SiC}$ crystal, it is the $\mathrm{Si}$ atom which is more susceptible to oxidation than the $\mathrm{C}$ atom, and it is the $\mathrm{Si}$ which is first oxidized forming $\mathrm{SiO}_{2}$.

Oxidation equilibrium diagrams could help to understand reactions during reentry of space vehicles. Since surface heating becomes significant at about $120 \mathrm{~km}$ from the Earth's surface, three layers of the atmosphere are involved, namely, the troposphere, stratosphere, and mesospherelower thermosphere. The $\mathrm{SiO}_{2}$ layer (probably formed in the initial phase of re-entry) protects the bulk $\mathrm{SiC}$ from further catastrophic oxidation to $\mathrm{SiO}$ which could occur at higher temperatures at the later stages. Protective action towards oxidation would be effective till below the melting point of $\mathrm{SiO}_{2}(1996 \mathrm{~K})$, where upon $\mathrm{SiO}_{2}$ liquid would be blown off the surface.

\section{Acknowledgments}

Financial support from ER \& IPR, DRDO, and Government of India is gratefully acknowledged.

\section{References}

[1] P. J. Jorgensen, M. E. Wadsworth, and I. B. Cutler, "Oxidation of silicon carbide," Journal of American Ceramic Society, vol. 42, no. 12, pp. 613-616, 1959.

[2] M. Auweter-Kurtz, G. Hilfer, H. Habiger, K. Yamawaki, T. Yoshinaka, and H. D. Speckmann, "Investigation of oxidation protected $\mathrm{C} / \mathrm{C}$ heat shield material in different plasma wind tunnels," Acta Astronautica, vol. 45, no. 2, pp. 93-108, 1999.

[3] Y. Song and F. W. Smith, "Effects of low-pressure oxidation on the surface composition of single crystal silicon carbide," Journal of the American Ceramic Society, vol. 88, no. 7, pp. 1864-1869, 2005.

[4] C. Virojanadara and L. I. Johansson, "Metastable oxygen adsorption on $\mathrm{SiC}(0001)-\sqrt{ } 3 \times \sqrt{ } 3 \mathrm{R} 30^{\circ}$," Surface Science, vol. 519, no. 1-2, pp. 73-78, 2002.

[5] J. A. Costello and R. E. Tressler, "Oxidation kinetics of hotpressed and sintered $\alpha$-SiC," Journal of the American Ceramic Society, vol. 64, no. 6, pp. 327-331, 1981.

[6] P. Mogilevsky and A. Zangvil, "Modeling of oxidation behavior of SiC-reinforced ceramic matrix composites," Materials Science and Engineering A, vol. 262, no. 1-2, pp. 16-24, 1999.

[7] D. M. Liu, "Oxidation of polycrystalline $\alpha$-silicon carbide ceramic," Ceramics International, vol. 23, no. 5, pp. 425-436, 1997.
[8] J. M. Powers and G. A. Somorjai, "The surface oxidation of alpha-silicon carbide by $\mathrm{O}_{2}$ from 300 to $1373 \mathrm{~K}$," Surface Science, vol. 244, no. 1-2, pp. 39-50, 1991.

[9] J. Wang, L. Zhang, Q. Zeng, G. L. Vignoles, and A. Guette, "Theoretical investigation for the active-to-passive transition in the oxidation of silicon carbide," Journal of the American Ceramic Society, vol. 91, no. 5, pp. 1665-1673, 2008.

[10] A. E. Mc Hale, Ed., Phase Equilibria Diagrams, Phase Diagrams for Ceramists, vol. 10, American Ceramic Society, Westerville, Ohio, USA, 1994.

[11] J. Weiss, H. L. Lukas, J. Lorenz, G. Petzow, and H. Krieg, "Calculation of heterogeneous phase equilibria in oxidenitride systems. I. The Quaternary System C Si N O," Calphad, vol. 5, no. 2, pp. 125-140, 1981.

[12] J. W. Chamberlain and D. M. Hunten, Theory of Planetary Atmospheres, Academic Press, San Diego, Calif, USA, 1987.

[13] R. D. Thompson, Atmospheric Processes and Systems, Routledge, London, UK, 1998.

[14] M. W. Chase Jr., NIST-JANAF Thermochemical Tables, vol. 14 of Journal of Physical and Chemical Reference Data, AIP, New York, NY, USA, 1985.

[15] C. Varadachari, "Constructing phase diagrams for silicate minerals in equilibrium with an aqueous phase: a theoretical approach," Soil Science, vol. 153, no. 1, pp. 5-12, 1992.

[16] C. Varadachari, "Fuzzy phase diagrams of clay minerals," Clays and Clay Minerals, vol. 54, no. 5, pp. 616-625, 2006.

[17] T. Narushima, M. Kato, S. Murase, C. Ouchi, and Y. Iguchi, "Oxidation of silicon and silicon carbide in ozone-containing atmospheres at $973 \mathrm{~K}$," Journal of the American Ceramic Society, vol. 85, no. 8, pp. 2049-2055, 2002.

[18] T. Narushima, T. Goto, and T. Hirai, "High-temperature passive oxidation of chemically vapor deposited silicon carbide," Journal of the American Ceramic Society, vol. 72, no. 8, pp. 1386-1390, 1989.

[19] L. Charpentier, M. Balat-Pichelin, and F. Audubert, "High temperature oxidation of $\mathrm{SiC}$ under helium with low-pressure oxygen-Part 1: sintered $\alpha$-SiC," Journal of the European Ceramic Society, vol. 30, no. 12, pp. 2653-2660, 2010. 

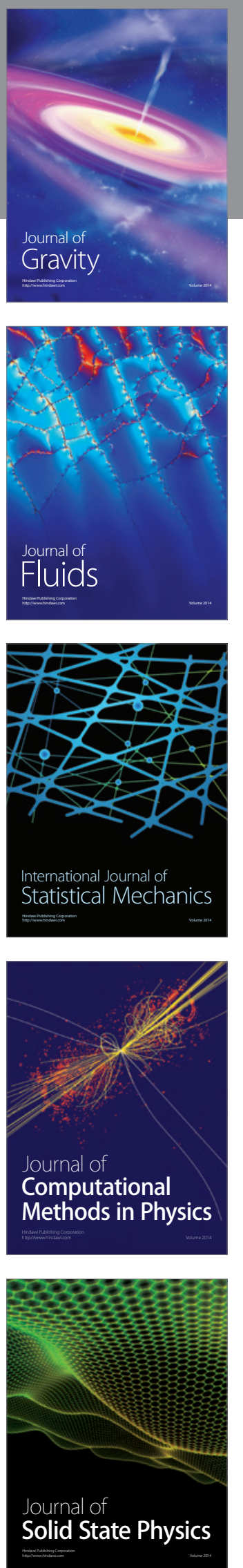
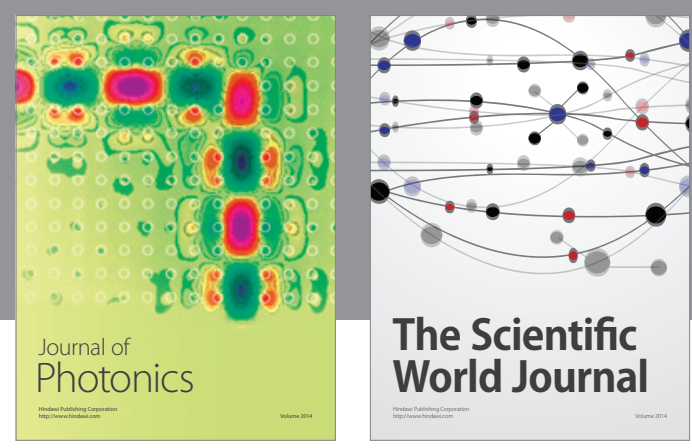

The Scientific World Journal

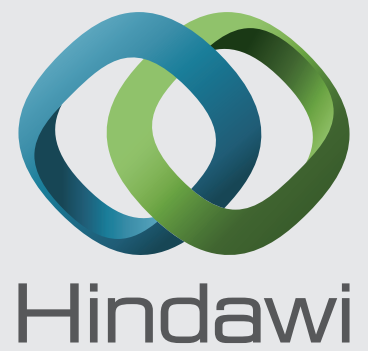

Submit your manuscripts at http://www.hindawi.com
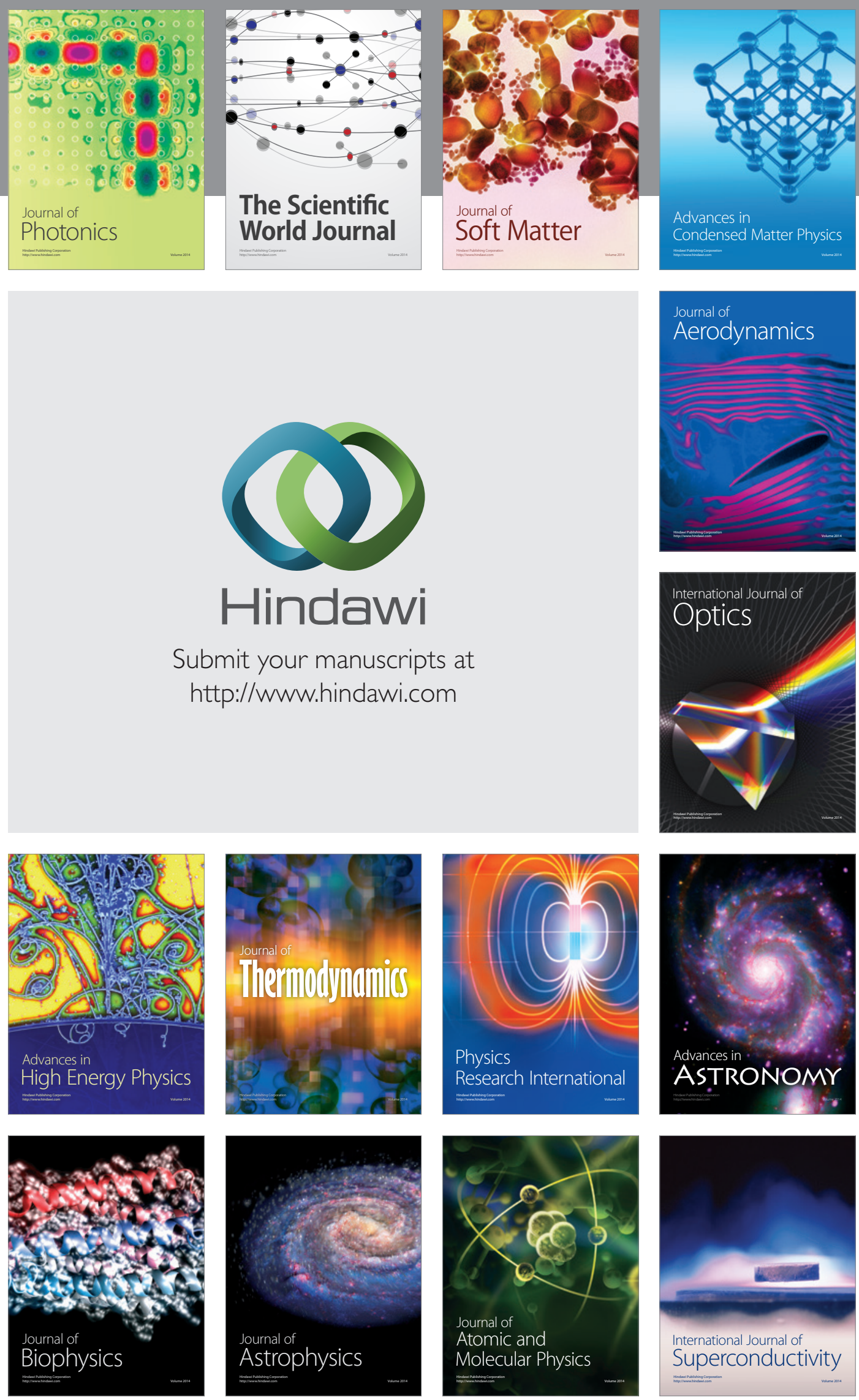
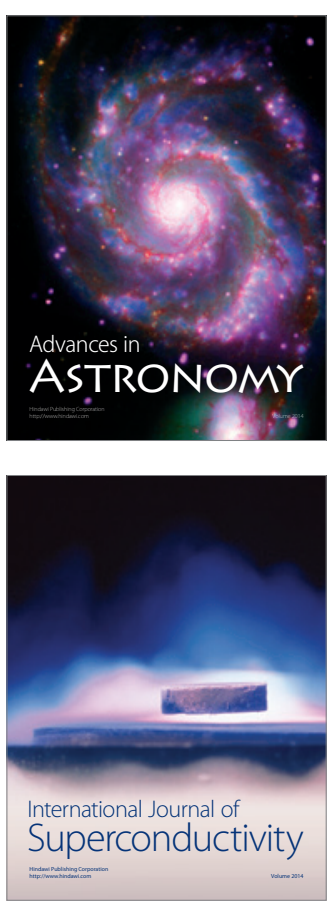